\title{
Hot Blast Flow Measurement in Blast Furnace in Straight Pipe
}

\author{
Ricardo S. N. Motta ${ }^{1}$, Edson C. Bortoni ${ }^{2}$, Luiz E. Souza ${ }^{3}$ \\ ${ }^{1}$ CSN/USS/UNIFEI, Volta Redonda, Brazil \\ ${ }^{2}$ ISEE/UNIFEI, Itajubá, Brazil \\ ${ }^{3}$ IESTI/UNIFEI, Itajubá, Brazil \\ Email: nadur@CSN.com.br, bortoni@unifei.edu.br,edival@unifei.edu.br
}

Received October 23, 2012; revised February 12, 2013; accepted August 22, 2013

Copyright (C) 2013 Ricardo S. N. Motta et al. This is an open access article distributed under the Creative Commons Attribution License, which permits unrestricted use, distribution, and reproduction in any medium, provided the original work is properly cited.

\begin{abstract}
This article shows an innovative method to model and validate the hot air flow through the blast furnacés tuyeres. This study will be the basis for flow measurements implementation and safety interlocks for the pulverized coal injection. The flow measurements were taken in the blast furnace down leg pipes by installing refractory Venturi tubes. The system for the calculation of differential pressure takes into consideration the dimension of the Venturi, the air density and compressibility. The objective is to specify the flow transmitters required to automate a control system and implement safety interlocks for the coal injection plant.
\end{abstract}

Keywords: Blast Furnacés Tuyeres; Straight Pipe; Hot Air Flow; Coal Injection

\section{Introduction}

The aim of this work is to create a valid calculation method to obtain a correct adjustment for the Delta $\mathrm{P}$ flow transmitters used in a special blast furnace equipment known as Straight Pipe Venturi (SPV). The SPV has got an internal refractory Venturi with differential impulse pressure pipes installed to reach the Venturi inlet and restrictions pressures.

The final subject is to implement safety interlocks for pulverized coal injection (PCI) in the blast furnace (BF). These researches and implementations were carried out in the BFs 2 and 3 of Companhia Siderúrgica Nacional (CSN) at Volta Redonda-Rio de Janeiro State-Brazil.

The hot blast air flow system in the straight tubes needs a differential pressure transmitter for the flow measurements to accomplish the safety interlocks of the BF with PCI. These intelligent analogical flow transmitters monitor the air blown through the straight pipes of each blowpipe. They will indicate if the tuyere is blocked or if the blast air flow is low for any reason.

For CSN's BF3, e.g., this low flow limit was initially established in $80 \mathrm{~m}^{3} / \mathrm{min}$ at NTP conditions. When this limit is reached, the coal valve in the distributor will close and a high pressure nitrogen valve for purge and cooling the lance will open, avoiding the accumulation of coal inside the down leg (also known as straight pipe) tubes and the blowpipe.

A blockage in the blowpipe or in tuyeres, due to crust accumulation of the injected or a not burning coal inside the straight and blowpipe tubes may cause a explosion at casthouse floor and a BF emergency stop.

In the calculation of this work, the real conditions of the air blown through the process were considered. The values and the methods were enhanced from Motta's [1], using considerations of Delmeè [2] and Bortoni [3].

\section{Nomenclature}

The nomenclature used is described below:

$T_{0}$-NTP temperature $(273 \mathrm{~K})$;

$P_{0}$-NTP pressure $(101.327 \mathrm{kPa})$;

Ts-Temperature of the hot blast air in $(\mathrm{K})$;

Ps-Pressure of the hot blast air in $\left(\mathrm{kgf} / \mathrm{cm}^{2}\right)$;

Z-Compressibility factor for the hot blast air;

$V_{1}, V_{2}$-Flow average speed in $(\mathrm{m} / \mathrm{s})$;

$Z_{1}, Z_{2}$-Highness in points 1 and 2 respectively in $(\mathrm{m})$;

$P_{1}, P_{2}$-Pressure in the points 1 and 2 ;

$G$-Gravity acceleration $=9.81\left(\mathrm{~m} / \mathrm{s}^{2}\right)$;

$\Delta P$-Differential pressure through the Venturi $(\mathrm{Pa})$;

$D$-Entrance internal pipe diameter in (m);

$d$-Restriction Internal pipe diameter in (m);

a-Restriction area of diameter $d$;

$\varepsilon$-Isentropic expansion factor; 
D'-Entrance Venturi diameter at $T_{S}$;

d'-Venturi diameter at $T_{S}$;

$\lambda_{\mathrm{H}}-\mathrm{SiC}_{2}$ dilation factor $=5.1 \times 10^{-6} \cdot{ }^{\circ} \mathrm{C}^{-1}$

$\lambda_{L}$-Alumina dilation factor $=6 \times 10^{-6} \cdot{ }^{\circ} \mathrm{C}^{-1}$

$Q$-Straight pipe flow measured in $\left(\mathrm{m}^{3} / \mathrm{min}\right)$;

$Q_{0}$-Straight pipe flow in $\left(\mathrm{m}^{3} / \mathrm{min}\right)$ at NTP;

$Q_{M}$-Motoblower flow in $\left(\mathrm{m}^{3} / \mathrm{min}\right)$ at NTP;

$Q_{T}$-Sum of straight pipe flows in $\left(\mathrm{m}^{3} / \mathrm{min}\right)$ at NTP;

$T_{a m b}$-Temperature where $D$ and $d$ are taken $\left(25^{\circ} \mathrm{C}\right)$;

$\rho_{\text {OAir }}$-Blown air density at NTP conditions $\left(\mathrm{kg} / \mathrm{m}^{3}\right)$;

$\rho_{\text {Air }}$-Air density at BF process conditions.

\section{Process Description}

The BF has the objective of extracting the hot metallic iron from ore, sinter, coke and coal. This is made by a hot enriched air flow passing through a burden of ore, coke, sinter and calcareous, that goes down in a internal column of the BF. The pulverized coal injection in the $\mathrm{BF}$ tuyeres replaces partially the coke charged on the top. The PCI increases the hot metal production and decreases the cost and environmental pollution, due to less coke needed.

The hot blast air is blown and distributed at the bottom of bf through the straight pipes, blowpipes and finally the tuyeres. This set is connected to the main bustle as Figure 1 shows. The air blown for the bf process is provided by the motoblowers. They blow atmosphere air into the hot stoves, and in this process, the temperature is raised up to about $200^{\circ} \mathrm{C}$. When this cold air passes through the hot stoves, temperature raises up to $1.100^{\circ} \mathrm{C}$ or $1.200^{\circ} \mathrm{C}$.

The hot air blow system is consisted of four hot stoves working in a parallel in a combination. While two are heating up, the other two are blowing hot air to the main bustle. The bustle has the purpose of distributing the heated up air from the hot stoves to the bottom of the BF. The main equipments of this set are the straight tubes, the blowpipes, the tuyeres coolers and the tuyeres themselves. The PCI lances goes beside the blow pipe and finally inside the tuyeres. The BF2 has got 24 tuyeres and BF3 has got 38. The hot blast air is distributed for each straight tube and creates a zone inside the BF. In this region, the pulverized coal is injected and burned.

The PCI system processes the raw mineral coal in granulometry to facilitate the pneumatic conveyer and combustibility. The pulverized coal is injected in the BFs by means of its lances through the tuyeres. It provides a reduced cost in the hot metal by the combustion of coal instead of coke.

The PCI interlocks for low flow has the objective of protecting the hot blast set against the accumulation of pulverized coal inside. If the flow is lower an alarm level, the coal valve is closed, in order to cool down the lance and mainly avoid the explosion of the blowpipe due to accumulation of not burned coal.
Table 1 shows CSN's blast furnaces hot blast flow variables and the analogical transmitters range adopted for each one of the BF's straight tubes

\section{Hot Blast Flow Density in the Blast Furnaces 2 and 3}

Blast flow fluid to be analysed in the flow equations is the hot air enriched typically with $3.6 \%$ of oxygen content. Thus, the typical chemical composition of the blast hot flow is:

Nitrogen $=75 \%$

Oxygen $=24.5 \%$

Argon and other gases $=0.5 \%$

This composition gives a molar mass of $29.049 \mathrm{~g} / \mathrm{mol}$. Once the hot blast flow is not a perfect gas, it is also necessary to introduce the compressibility factor in order to correct the deviations of the volume expansion in relation to the perfect gas.

The molar mass of the hot air composition gives the compressibility factor of 1.0008 for the BF2 and 1.0012 for the BF3. As can be seen, all the calculations must be done using at least four digits after the point. Those compressibility factors are used to calculate the hot air density by the Equation (1) for the temperature and pressure conditions of the blow process.

$$
\rho_{A R}=\rho_{0 A R} \frac{T_{0} P_{S}}{T_{S} P_{0} Z}
$$

For the NTP conditions, in agreement with [1], the density of the hot blast air has got the following values:

\section{A-For the Blast Furnace 3:}

$$
\rho_{\text {AIR }}=1.2939 \frac{\mathrm{kg}}{\mathrm{m}^{3}}
$$

B-For the Blast Furnace 2:

$$
\rho_{\text {AIR }}=0.8113 \frac{\mathrm{kg}}{\mathrm{m}^{3}}
$$

\section{Flow Calculation for the BF Process}

The mathematical model development for the differential pressure calculation to be set up in the analogical transmitters flow takes into account the hot blast fluid density, the chemical composition of the fluid and the dilation factor of refractory Venturi.

The system used to proceed the mathematical analyses is shown in Figure 2. It was developed using the con-

Table 1. CSN's BFs pressure and flow.

\begin{tabular}{ccccc}
\hline BF & $\begin{array}{c}T_{S} \\
\left({ }^{\circ} \mathrm{C}\right)\end{array}$ & $\begin{array}{c}P_{S} \\
\left(\mathrm{kgf} / \mathrm{cm}^{2}\right)\end{array}$ & $\begin{array}{c}Q_{s} \\
\left(\mathrm{Nm}^{3} / \mathrm{min}\right)\end{array}$ & $\begin{array}{c}\text { Range } \\
\left(\mathrm{Nm}^{3} / \mathrm{min}\right)\end{array}$ \\
\hline 2 & 1200 & 2.5 & 3200 & 0 to 200 \\
3 & 1100 & 4.2 & 6800 & 0 to 300 \\
\hline
\end{tabular}




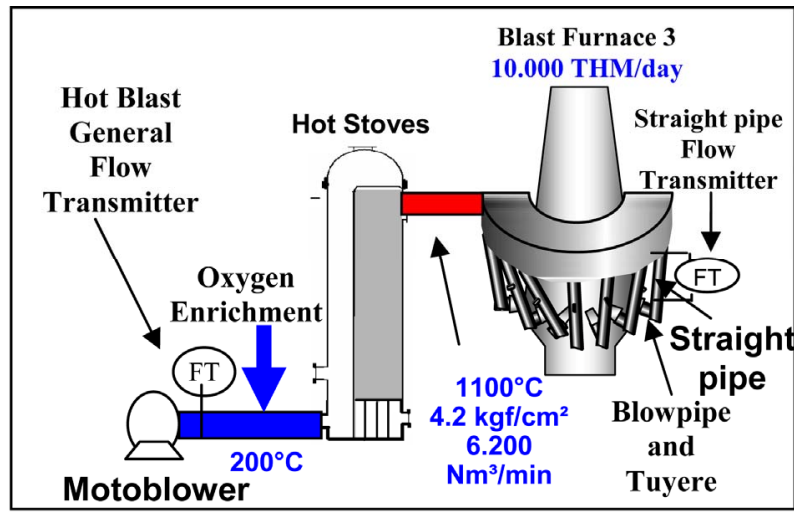

Figure 1. Hot blast air system for CSN's blast furnace 3 .

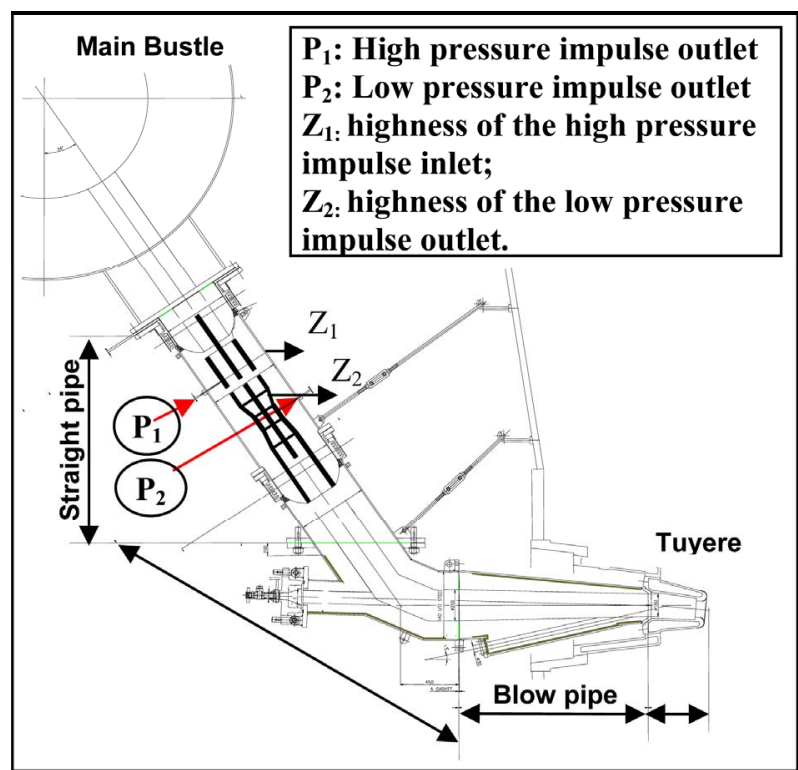

Figure 2. Hot blast air set equipment for a blast furnace.

servation energy principle in the stationery state as used in Singlueri and Nishinori [4].

The Equation (2) is also known as Bernoulli's equation. It is the base for taking into account all the considerations made previously.

$$
\frac{V_{1}^{2}}{2}+G z_{1}=\int_{1}^{2} \frac{\Delta P}{\rho_{\text {AIR }}}+\frac{V_{2}^{2}}{2}+G z_{2}+W_{s}+\operatorname{Losses}_{1-2}
$$

The approach has the following considerations to proceed:

D The work accomplished in the Venturi Tube is zero: $\left(W_{s}=0\right)$;

$>$ The pressure losses by friction are despised:

$>\left(\right.$ Losses $\left._{1-2}=0\right)$;

$>$ The pressure drop due to the height difference $H$ between the takings of high and low pressure impulse pipes is smaller when compared to the Venturi's drop pressure, $\Delta P$.

In Motta [1], the approaches regardless the fluid den- sity, molar mass, temperature and pressure process and the effects of hot blast air compressibility are despised. In this work, the hot air density and chemical composition were added up in agreement with the temperature and process conditions incorporating the effects of the hot blast air compressibility factor. They are distinctly considered for each BF, just as (1) showed. The practical works at the field were implemented according to this article guide lines in two industrial plants (two BFs).

The flow through the Venturi pipe in $\left(\mathrm{m}^{3} / \mathrm{s}\right)$ can be obtained by the Equation. (1) for the perfect gases. Replacing this result in (2), the speed $V_{2}$ can be isolated in the continuity equation, and multiplying the result by the restriction area value.

Some existing effects must also be considered in the friction of the air inside the Venturi restriction. Because of these effects, the real pressure drop will be greater than considered in Equation (2). Therefore, for this correction, a multiplication coefficient for the theoretical flow must be inserted. This coefficient is known as $C_{d}$ (Discharge coefficient). Initially, it will be considered $C_{d}=$ 0.99593. This number also depends on the aerodynamic of the refractory material restriction.

Besides those considerations, there is the isentropic expansion factor that takes into account the hot blast air compressed inside the Venturi restriction where the pressure and density go down.

Then, the flow real calculation expression in the straight tube is given by the Equation (3) below:

$$
Q=C_{d} a \varepsilon \sqrt{\frac{2\left(\frac{\Delta P}{\gamma}+G H\right)}{1-\left(\frac{d}{D}\right)^{4}}}
$$

where

$$
\Delta P=P_{1}-P_{2} \text { and } H=Z_{1}-Z_{2}
$$

In the projected system, the compressibility effects of the air were included mathematically in the analyses for the correction of the air density. The value of $2 \mathrm{GH}$ can be despised as done in [2-4] because its value is insignificant regarding to $\Delta P$ in the restriction.

The primary measurement element of the projected flow is a moulded ceramic Venturi inside the straight tube, just as showed in the Figure 2. The impulse outlet pipelines of high and low pressure are conducted up to the differential pressure transmitters shelter room which provides the flow measurement of each SPV.

Another important factor is the Venturi material thermal dilation. This affects the internal dimensions $D$ and $d$ according to the hot blast air temperature. These thermal dilation coefficients are different for each dimension of $\mathbf{D}$ and $\mathbf{d}$, because the materials in those points are silicon 
Carbide $\left(\mathrm{SIC}_{2}\right)$ upper part and Alumina in the restriction part $\left(\mathrm{AL}_{2} \mathrm{O}_{3}\right)$.

Therefore, those materials have got different dilation coefficients. Equations (4) and (5) below correct the dimensions $\mathbf{D}$ and $\mathbf{d}$ according to the BF blast temperature.

$$
\begin{gathered}
D^{\prime}=D\left(1-\lambda_{H}\left(T_{S}-T_{a m b}\right)\right) \\
d^{\prime}=d\left(1-\lambda_{L}\left(T_{S}-T_{a m b}\right)\right)
\end{gathered}
$$

With all these considerations, the hot air blast through the refractory Venturi, Equation (3), can be calculated again with the new dimension $\mathbf{D}$ and $\mathbf{d}$ given by the Equations (4) and (5). Finally the practical value of $\Delta \mathbf{P}$ for adjustment in the analogical flow transmitter can be just as the Equation (6) below:

$$
\Delta P=\frac{\rho_{A I R}}{2} \times\left(\frac{Q}{C_{d} a \varepsilon}\right)^{2} \times\left[1-\left(\frac{d^{\prime}}{D^{\prime}}\right)^{4}\right]
$$

\section{Differencial Pressure for BF3}

The characteristics of the hot air blast along BF 3 straight tube together with the flow range at NTP required for the instrument, $Q_{0}=300\left(\mathrm{~m}^{3} / \mathrm{min}\right)$, must be considered in the Equation (3). Therefore, the equation of the perfect gas has to be used to obtain the hot air real value, real $Q$, and the real BF 3 process variables as shown in Equation (7) below:

$$
\frac{P_{S} Q}{T_{S} Z}=\frac{P_{0} Q_{0}}{T_{0}}
$$

The differential pressure calculation for the analogical flow transmitter calibration in BF3 blast conditions is now described using Equations (1), (4), (5), (6) and (7).

$$
Q=299\left(\frac{\mathrm{m}^{3}}{\min }\right)=5\left(\frac{\mathrm{m}^{3}}{\mathrm{~s}}\right)
$$

The internal Venturi dimensions data of BF3 straight tube, and the other data are applied in Equation (6). With this new method and considerations, the differential pressure to calibrate the BF3 SPV flow transmitter:

$$
\Delta P=24577.8(\mathrm{~Pa})=2506.24\left(\mathrm{mmH}_{2} \mathrm{O}\right)
$$

\section{Differential Pressure for BF2}

In the $\mathrm{BF} 2$, the range chosen for the digital control system (DCS) is 0 to $200 \mathrm{~m}^{3} / \mathrm{min}$. The blast hot air temperature $\left(1.127^{\circ} \mathrm{C}\right)$ and blast pressure $\left(2.5 \mathrm{kgf} / \mathrm{cm}^{2}\right)$ have to be renormalized to determine the flow value, and then, to obtain the differential pressure, $\Delta P$, to adjust the straight flow transmitters in the field.

The unit to adjust the differential pressure flow transmitters is generally given in $\mathrm{mmH}_{2} \mathrm{O}$.

$$
Q=318.8\left(\frac{\mathrm{m}^{3}}{\min }\right)=5.31\left(\frac{\mathrm{m}^{3}}{\mathrm{~s}}\right)
$$

With all these values, it is possible to obtain the value for the BF2 differential pressure from (4), (5) and (6). For the flow range from 0 up to $200 \mathrm{~m}^{3} / \mathrm{min}$, in the BF2, the differential pressure for the flow transmitter is:

$$
\Delta P=13767.5(\mathrm{~Pa})=1403.89 \mathrm{mmH}_{2} \mathrm{O}
$$

\section{New Safety Interlocks for PCI}

To operate PCI in a safe way, the interlocks for low flow in the SPV are essential as shown in the works of Johansson and Medvedev [5], Birk, Johansson and Medvedev [6]. This is so because the coal combustion is only assured when there is race-way presence.

Here are the main implementations make to improve the PCI interlocks for coal injection. Any of these conditions watched by the DCS will close the coal valve and open the nitrogen purge valve. This will be locked until operator's acknowledge, like a RS flip-flop as shown in the logics of Figure 3:

A-Low flow alarm: Basic engineering. It is the original designed by the PCI supplier and for most of PCI plants;

B - High flow alarm: New implementation. It is used to detect the clogged of high impulse pipe pressure;

C-Measurement loop opened: This alarm detects if the SPV flow transmitter wiring has broken or is damaged;

D-Measurement loop short circuited: This alarm detects if the SPV flow transmitter has got a short circuit;

$\mathbf{E}$-High negative deviation: If the flow goes down suddenly but does not reach the low level. That may mean falling scaffold (skull) in front of the tuyere and the coal valve has to be closed.

F-High positive deviation: This alarm is used with the same purpose of negative deviation. However, it can be also used or radically to see if the blow pipe has blown off.

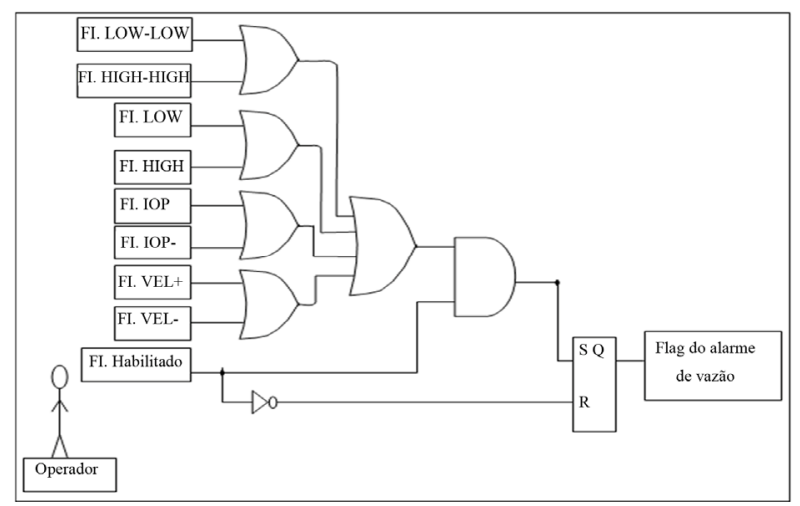

Figure 3. New interlocks for safety PCI plant. 


\section{Validation of the Method}

One of the means to prove the method and the formulas is to get the obtained measurements and make the sum of 38 flow values of straight tubes for the BF3 and 24 flow values for the BF2 as shown in the general Equation (8) below:

$$
Q_{T}=\sum_{i=1}^{24} Q_{i}
$$

These two sums values have been used to compare to the general flow measurement signal coming from the motoblowers. The motoblowers general flow measurement $\left(Q_{M}\right)$ has got an error of less than $0.1 \%$ and those signals from $\mathrm{BF} 2$ and $\mathrm{BF} 3$ were sent to $\mathrm{PCI}$.

The motoblowers flows measurements were compared to the addition of individual flows from each straight tube. This procedure was used to validate the developed model of flow measurement in the straight pipe in the CSN's BF.

Deviation of those two signals, or percentual difference, is calculated in order to know how right the individual measurement is. Equation (9) shows this percentual deviation which will be used to evaluated how waste the refractory Venturi is.

$$
D V \%=\frac{Q_{M}-Q_{T}}{Q_{T}} \times 100 \%
$$

Two graphic screens were implanted in PCI's DCS illustrating the flow profiles in a radial graph for each blast Furnace. The obtained real values are shown at the left side in Figures 4 and 5. At the start, some of the tuyeres were without the flow measurements due to damages in the Venturi, and the others were isolated for operational issues (hot points in the hearth) like in Figure 5.

Two graphic screens like Figure 6 were implanted in DCS illustrating the bar graph flow and the alarms.

\section{Influence of Restriction Waste in the Flow Measurement}

In the beginning of the research, the sum of the down leg flows was $15 \%$ smaller than the flow obtained by the motoblowers general flow. It comes to the conclusion that refractory Venturi suffers waste or erosion with the hot air blow. The restriction of diameter Venturi $d$ tends to wear away as time goes by. If it approaches to diameter $\mathrm{D}$, the differential pressure of the flow measurement will decrease.

The influence of the restriction waste on the straight tube internal Venturi in the flow measurement was studied. The study also determines the lifetime of the blast furnace straight Venturi tube, SPV, usually now around five years. Then, the inlet refractory material was changed to silicon carbide to provide higher waste resistance.

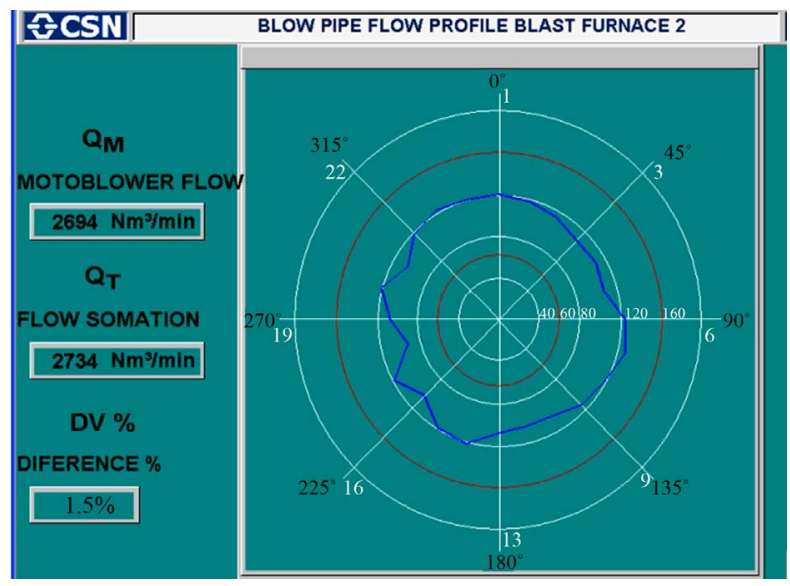

Figure 4. BF2 flow profile of the flows measurements.

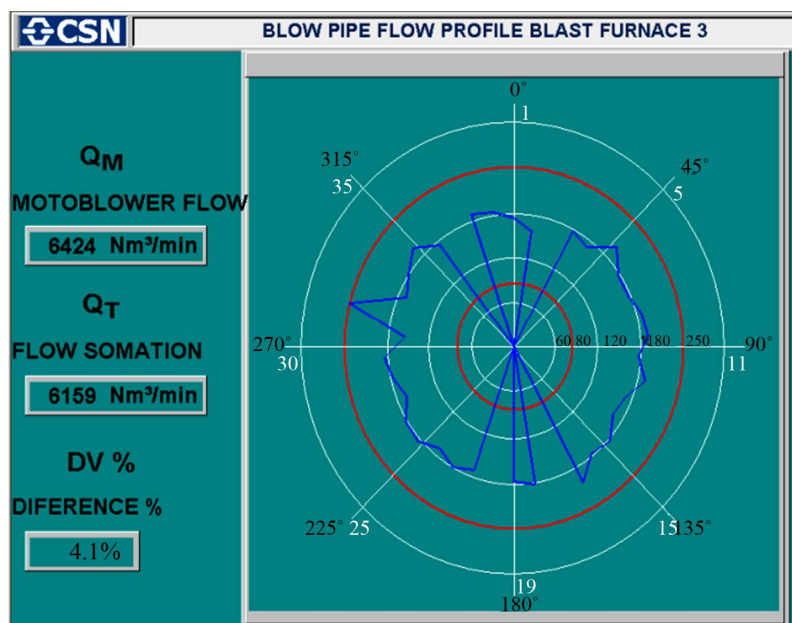

Figure 5. BF3 flow profile of the flows measurements.

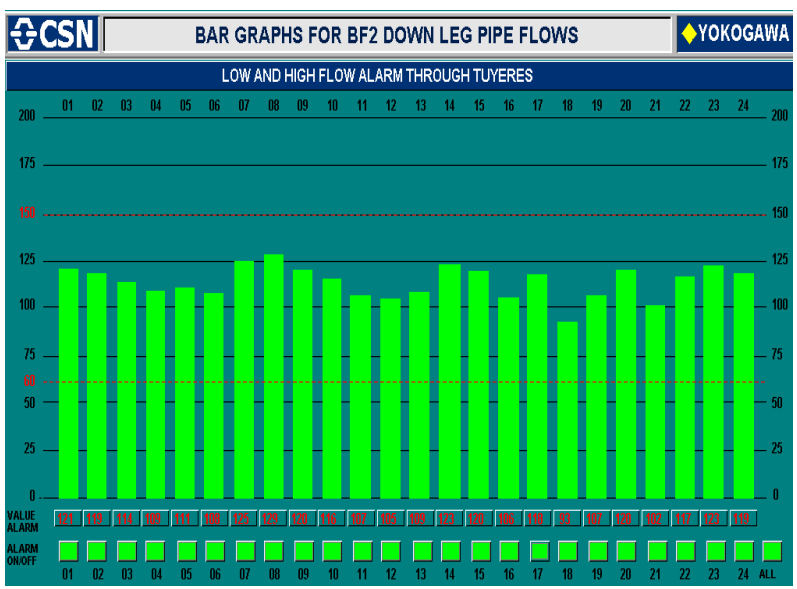

Figure 6. Bar graphs for BF2 straight pipes.

Down Leg flow measurement is affected by the relation $\mathbf{d} / \mathbf{D}$, which means, while the Venturi gets wasted, the value $\mathbf{d}$ of the restriction approaches to the pipeline normal diameter $\mathbf{D}$ and the flow measurement decrease along the time. Figure 7 shows how the flow measure- 


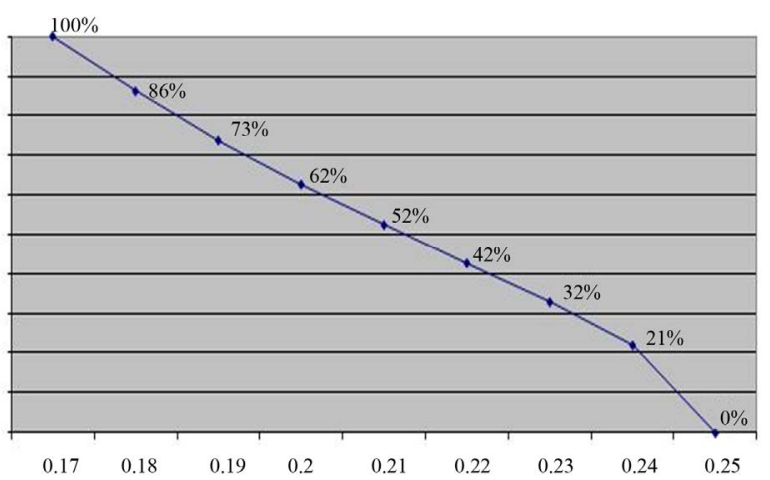

Figure 7. Flow measurement iinfluence by the $\mathrm{d}$ waste.

ment is affected in percentage (DV\%-Equation (9)) according to the $\mathbf{d}$ waste as it approaches to the $\mathbf{D}$ diameter.

\section{Evaluation of the Results}

The main results were the calculations memorial and the gauging of hot blast flow measurement system through the tuyeres seeking to have safety interlocks demanded by the coal injection process.

Another result of this work was the flow distribution profiles in section of each blast furnace tuyeres illustrated in the graph screens of DCS shown in 4 and 5, as well as a real time comparison model of the measurement additions, with the general measurement coming from motoblower plant.

In the BF3, the missed flow measurement propitiated an interlock for the lances of pulverised coal injection. This was verified by applying a new identification and adjustment method, where the individual flow additions of each tuyere's transmitters were compared to the cold air general flow transmitter coming from the motoblower system.

In the BF2, there were many alarms for high flow in the straight tubes, due to many stopped tuyeres, the flow had its value increased in each one of the remaining straight tubes, easily achieving its interlock values for high flow, that's why the flow scale was increased from 160 to $200 \mathrm{~m}^{3} / \mathrm{min}$, these values are found in Table 1 .

\section{Discussion}

Motta [1] had the aim of developing the differential pressure flow measurement for blast furnace using basic parameters and variables. However, there was no method for the validation. In this work, the analogical flow transmitters were implemented and the obtained results were more precise, in the fittings, for considering the real conditions of the blow, as density of the blown air flow, pressure, temperature, viscosity of the air, friction of the air with the Venturi tube and the inertia.

The only difficulty is to keep the system since the restriction of the straight pipe wastes along the time, and therefore the straight pipe must be changed every two or three years to maintain its operation and the essential safety interlocks.

\section{Conclusions}

The modelling for the calculation of the straight tubes flow transmitters differential pressure measurement in the Blast Furnace was made with large precision taking into account all possible variables.

The validation method has got a new approach and the safety PCI interlocks are the high lights of this innovating work. The blast air and feed back of the flow measurement model were compared to each other.

The reference is to change the straight pipe during the Blast Furnace stop. Besides, the refractory Venturi waste can be evaluated along the years and it is used to program the change of the most wasted straight pipe.

The new developments showed that the SPV with double refractory type, the methods and formulas to calculate the $\Delta \mathbf{P}$ parameter, the validation method and the new safety PCI interlocks were created due to a lot of mess and trouble caused by explosions in the past tense.

Those explosions and down legs full of coals have never been noticed again, since the implementation of the actions described here along the last five years.

All the methods and safety interlocks implementations performed here in this article can be reproduced and implemented in any blast furnace with coal injection system around the world. The cost of the implementation is worthy when compared to the new blast furnace safety operational conditions for PCI.

\section{REFERENCES}

[1] M. et Alli, "Modeling of the Measurement of Flow Measurement of the Flow of Hot Air in Straight Tube of Blast Furnace," 39th Seminar of Reduction of Ore of Iron and Raw Materials, Ouro Preto, 22-26 November 2009, pp. $1-10$.

[2] G. J. Delmée, "Manual de Mediçao de Vazão," Editora Edgard Blücher Ltda, São Paulo, 1983.

[3] E. C. Bortoni and Z. Souza, "Instrumentation for Energy and Industrial Systems," Editora Novo Mundo Ltda, Itajubá, 2006.

[4] L. Siglüeri and A. Nishinori, "Controls Automatic of Industrial Processes," Edgard Blücher Ltda, São Paulo, 1992.

[5] A. Johansson and A. Medvedev, "Detection of Incipient Clogging in Pulverised Coal Injection Lines," IEEE Transactions on Industry Applications, Vol. 36, No. 3, 2000, pp. 877-883. http://dx.doi.org/10.1109/28.845065

[6] W. Birk, A. Johansson and A. Medvedev, "Model-Based Goes to Fine Coal Injection Plant," IEEE Control Systems Magazine, Vol. 19, No. 1, 1997, pp. 33-43.

http://dx.doi.org/10.1109/37.745765 